\title{
Emergencies after endoscopic procedures
}

\author{
Carla Rolanda, MD, PhD, Assistant Professor, Medical \\ Doctor $^{\text {a, b, c, *, Ana C. Caetano, MD, Medical Doctor }}{ }^{\mathrm{a}, \mathrm{b}, \mathrm{c}}$, \\ Mário Dinis-Ribeiro, MD, PhD, Associate Professor ${ }^{\text {d, e }}$ \\ a Department of Gastroenterology, Hospital Braga, Braga, Portugal \\ ${ }^{\mathrm{b}}$ Life and Health Sciences Research Institute (ICVS), School of Health Sciences, University of Minho, \\ Braga, Portugal \\ c ICVS/3B's - PT Government Associate Laboratory, Braga/Guimarães, Portugal \\ d Portuguese Oncology Institute of Porto, Porto, Portugal \\ e CIDES/CINTESIS, Faculty of Medicine of University of Porto, Porto, Portugal
}

\section{Keywords:}

GI endoscopy adverse events

GI emergencies

Bleeding

Haemorrhage

Perforation

Infection

Embolization

Diagnosis and management of severe complications

\begin{abstract}
A B S T R A C T
Endoscopy adverse events (AEs), or complications, are a rising concern on the quality of endoscopic care, given the technical advances and the crescent complexity of therapeutic procedures, over the entire gastrointestinal and bilio-pancreatic tract. In a small percentage, not established, there can be real emergency conditions, as perforation, severe bleeding, embolization or infection. Distinct variables interfere in its occurrence, although, the awareness of the operator for their potential, early recognition, and local organized facilities for immediate handling, makes all the difference in the subsequent outcome. This review outlines general AEs' frequencies, important predisposing factors and putative prophylactic measures for specific procedures (from conventional endoscopy to endoscopic cholangio-pancreatography and ultrasonography), with comprehensive approaches to the management of emergent bleeding and perforation.
\end{abstract}

(c) 2013 Elsevier Ltd. All rights reserved.

\section{Introduction}

Both patients and practitioners expect their endoscopy procedures go according to plan. However, for several reasons some patients experience complications or, as correctly mentioned, adverse events

\footnotetext{
* Corresponding author. Surgical Sciences Research Domain, Life and Health Sciences Research Institute (ICVS), School of Health Sciences, University of Minho, Campus de Gualtar, Braga 4709-057, Portugal. Tel.: +351 939912301.

E-mail address: crolanda@ecsaude.uminho.pt (C. Rolanda).
} 
(AEs) [1]. Even though there is substantial literature describing series of AEs, well-designed prospective trials and a standardized nomenclature with agreed-on definitions are lacking [1-3].

Recently an AE was defined as a situation that prevents completion of the planned procedure and/or results in admission to hospital, prolongation of existing hospital stay, another procedure (needing sedation/anesthesia), or subsequent medical consultation. AEs are distinct from incidents, also unplanned events, but that do not interfere with completion of the procedure; an example of this includes bleeding that stops spontaneously or with endoscopic therapy during the procedure. Concerning the timing, AEs can occur pre-, intra- (from entering the preparation area through leaving the endoscopy room), post- (up to 14 days), and late-procedure (any time after 14 days, usually up to 30 days) [1,2].

In this manuscript, we will discuss emergent AEs after endoscopic procedures - serious and unexpected situations that demands immediate action. Although cardiopulmonary and sedation-related events account for more than $50 \%$ of the severe morbidity and mortality related to gastrointestinal (GI) endoscopy [4], this document will focus only on major AEs related to endoscopic equipment direct harm, mainly haemorrhage, perforation, infection and embolization. Even though no sufficient consensus exists in most cases, we outlined the predisposing factors and putative prophylactic measures with comprehensive approaches to their management.

\section{AEs during diagnostic vs therapeutic GI endoscopy}

Diagnostic GI endoscopy is generally safe. For upper GI endoscopy, the overall AEs and mortality rates were reported as $0.13 \%$ and $0.004 \%$ respectively, being 10 times higher for therapeutic interventions [5]. General AEs in diagnostic colonoscopy ranges from $0.02 \%$ to $0.07 \%$ [6]. See Table 1 which summarizes the frequencies, described in literature, of severe/emergent AEs. Considering the main complications under discussion, although there is no question about the emergent character of perforation, we are not able to discriminate the real severity of haemorrhage rates reported in literature; this fact is even more remarkable when looking for infection and embolization as a result of its rarity.

\section{Haemorrhage}

Haemorrhage is rare in diagnostic procedures. In upper GI endoscopy, Mallory-Weiss tears cause bleeding in less than $0.5 \%$ when excessive retching and struggling occur, however those are not

Table 1

Available frequencies of severe/emergent AEs (\%).

\begin{tabular}{|c|c|c|c|c|}
\hline & Haemorrhage & Perforation & Infection $^{\mathrm{a}}$ & Embolization \\
\hline \multicolumn{5}{|l|}{ Diagnostic GI endoscopy } \\
\hline Upper GI & $0.002-0.06$ & $0.0009-0.04$ & - & - \\
\hline Colonoscopy & $0-0.03$ & $0.005-0.2$ & - & - \\
\hline \multicolumn{5}{|l|}{ Therapeutic procedures } \\
\hline Polipectomy (upper/lower) & $3.4-10.0 / 0.26-6.1$ & $0.06-1.1$ & - & - \\
\hline ESD (upper/lower) & $1.8-15.6 / 0-12.0$ & $1.3-4.0 / 1.4-10.4$ & - & - \\
\hline Stenting (upper/lower) & $0-3.9$ & $0-0.8 / 3.8-10.0$ & - & - \\
\hline Dilation & - & $0-4.0$ & - & - \\
\hline Gastrostomy (jejunostomy) & $0-1.0$ & - & $7.0-47.0$ & - \\
\hline Variceal ligation/sclerosis & - & $0-0.7 / 2.0-5.0$ & - & $0-1.0$ \\
\hline APC/RFA ablation & $0-4.0 / 0-2.0$ & $0-2.0$ & - & - \\
\hline \multicolumn{5}{|l|}{ Enteroscopy } \\
\hline Diagnostic & $0-0.8$ & $0-0.3$ & - & - \\
\hline Therapeutic & $0-3.0$ & $0-4.0$ & - & - \\
\hline \multicolumn{5}{|l|}{ ERCP } \\
\hline Diagnostic & 0 & 0.11 & - & - \\
\hline Therapeutic & $0.49-2.0$ & $0.3-0.8$ & $0.5-3.0$ & Rare reports \\
\hline \multicolumn{5}{|l|}{ EUS } \\
\hline Diagnostic plus FNB & $0.15-3.7$ & $0.03-0.86$ & $0-16.0$ & - \\
\hline
\end{tabular}

ESD - endoscopic submucosal dissection; APC - argon plasma coagulation; RFA - radiofrequency; FNB - fine needle biopsy.

a Infection - rates resolved under adequate antibiotic prophylaxis for specific procedures. 
clinically significant [7]. Globally, it may be more likely in individuals with thrombocytopaenia and/or coagulopathy. Therefore, some authors recommend that diagnostic endoscopy can be performed when the platelet level is $20,000 / \mathrm{ml}$ or greater and that a threshold of $50,000 / \mathrm{ml}$ should be considered before performing biopsies $[3,8]$.

\section{Perforation}

Perforation may occur in less than $0.04 \%$ of the diagnostic upper GI endoscopy, and is usually associated to operator inexperience and some patient-related risk factors, such as: cervical osteophytosis, Zenker's or duodenal diverticulum, pharyngeal pouches, malignant/benign strictures and eosinophilic oesophagitis [9-12]. In colonoscopy the risk of perforation ranges from $0.11 \%$ in diagnostic, up to $10 \%$ in therapeutic procedures [6,13-15]. There are three main mechanisms for the occurrence: pneumatic/barotrauma, mechanical pressure, and post-therapeutic fragile wall. The patient-related risk factors contributing to perforation are well established and include: advanced age, female sex, diverticular disease, previous abdominal surgery, colonic strictures and therapeutic procedures $[13,16]$. The main location is the rectosigmoid in more than $2 / 3$ of perforations $[16,17]$.

\section{Infection}

Infection is a rare $\mathrm{AE}$ that can result from the procedure itself (translocation or failure to follow guidelines for the reprocessing) or the use of endoscopic devices and accessories. Transient bacteraemia has been reported at high rates, but the frequency of endocarditis or other clinical infections is extremely low [18-20]. Antibiotic prophylactic regimens are only recommended for specific interventions and should be strictly followed: suspected incomplete biliary drainage, puncture of fluid collections or cysts, percutaneous endoscopic feeding tube placement, and cirrhotic patients with upper GI bleeding [21].

\section{Embolization}

Embolization is mainly related to specific therapeutic interventions. Variceal sclerosis may cause extension of thrombus into the portal and mesenteric venous systems [22] and cyanoacrylate injection has been reported as a cause of systemic emboli to lung, spleen and portal vein [23,24]. ERCP-induced air embolism is extremely rare although severe fatal complications, causing immediate cardiopulmonary collapse have been reported [25].

\section{Specific therapeutic procedures}

\section{Polypectomy}

The main AE in polypectomy is bleeding. Usually intra-procedure in gastric lesions, occurring in $3.4 \%$ to $7.2 \%$ and delayed in duodenum, reported in $3.1 \%-22 \%$ of patients [2,26]. In colorectal polypectomy, bleeding occurs in $0.3 \%$ to $6.1 \%$ [27]. Evidence that aspirin or NSAIDs increase the risk of bleeding after polypectomy is lacking. The reader is referred to guidelines concerning the management of anticoagulation and antiaggregant therapy during endoscopy [28]. The bleeding risk also depends on the type and the size of the polyp and the technique of polypectomy. Immediate bleeding can be prevented by the use of pure coagulation, epinephrine injection, clipping or endolooping the stalk, but no prophylactic measures have proved to be efficient in preventing delayed bleeding [5].

\section{Endoscopic mucosal resection (EMR)/endoscopic submucosal dissection (ESD)}

EMR (snare, cap, and ligature) is used to resect focal lesions of the mucosa up to the submucosal layer. The overall incidence of serious AEs such as bleeding, perforation and stricture was estimated to be between $0.5 \%$ and 5\% [29]. Bleeding occurs more often with multifocal EMR and gastric EMR, however delayed bleeding is rare $(<5 \%)$ in these locations comparing to duodenum which rates 
between $4 \%$ and $33 \%$ [30]. It can be prevented by revision of the site of resection at the end of the procedure, coagulating any visible vessel, closing mucosal defects with clips and by therapy with proton pump inhibitor (PPI). Gastric EMR perforation is reported more frequently than in oesophageal EMR, possibly because of larger lesions in the stomach [31].

In ESD AEs are similar to those described for EMR, although with greater frequency given the larger areas of resection. The overall incidence of bleeding and perforation with ESD is $11 \%$ and $6 \%$ respectively [32-34]. Due to the widespread acceptance of gastric and oesophageal ESDs, the number of medical facilities that perform colorectal ESDs grew in recent years $[35,36]$. The reported rate of perforation is $1.4-10.4 \%$ which is associated with large tumour size ( $>30 \mathrm{~mm}$ ) and the presence of fibrosis. In order to reduce the perforation rate for colorectal EDS, the use of specialized knives, distal attachments and hypertonic solutions, is recommended because of the thinner colonic wall [35].

\section{Dilation}

The most common AEs related to dilation are perforation, haemorrhage, aspiration and bacteraemia. Aspiration of retained food and fluid can be an emergency, thus it should be prevented by prolonged fasting, suction, drainage, an anti-Trendelenburg position, or airway tube protection. Bleeding is usually self-limited. Despite the high frequency of bacteraemia, infectious sequelae are rare [37,38]. Thus, perforation is the most relevant $\mathrm{AE}$ in dilation.

In the oesophagus, the risk of perforation in malignant, radiation-induced and post-causticingestion strictures is twice that of peptic strictures. Complex strictures (asymmetric, longer, $<12 \mathrm{~mm}$ in diameter) are also associated with increased rates of complications [39]. Dilation of eosinophilic oesophagitis is frequently associated with mucosal tears, but not perforation [40]. Although the wire-guided polyvinyl dilators and through-the-scope balloons have similar rates of efficacy and AEs, the operator's experience level alters significantly the perforation risk [9]. Stepwise increase of balloon diameter may help reducing the risk. In achalasia, perforation rates up to $4 \%$ were described for pneumatic dilation. These rates may be reduced by starting with a $30 \mathrm{~mm}$ balloon, progressing only if symptoms do not improve and never using a balloon larger than $35 \mathrm{~mm}$ [41]. Perforation rates in benign gastric outlet obstruction are high as 7.4\%, risk factors are dilation in the setting of active ulceration and balloon size greater than $15 \mathrm{~mm}$ [42]. In lower gastrointestinal strictures' dilation, mostly in anastomosis and in Crohn's disease, the perforation is more often reported with $25 \mathrm{~mm}$ balloons $[43,44]$.

\section{Stenting}

Stents can be deployed in any part of the GI tract and are currently used for malignant, benign stenosis, and closing fistulas [45]. Immediate AEs of oesophageal self-expandable metal stents (SEMSs) occur in $2-12 \%$ of patients and include aspiration, pain, respiratory compromise and improper positioning. These AEs may be minimized by adequate patient preparation and positioning, familiarity with the stent, use of soft-tipped guide-wires, and avoidance of aggressive dilation [46]. Late AEs occur in $20-40 \%$ of patients: regurgitation when the gastro-oesophageal junction is bridged, occlusion, migration and perforation. The risk of late perforation and bleeding seems to be higher with larger stents, although larger stents decrease the rate of migration and tumour ingrowth [47]. Pre-treatment with chemoradiotherapy was reported to increase the incidence of AEs by some authors, but not by others. Gastroduodenal stents are associated with similar AEs, and severe events as bleeding and perforation occur in $1-5 \%$ of patients $[48,49]$. Also colonic stents have similar particularities; they are applied in acute malignant obstruction as bridge to surgery, with a high rate of clinical (6.9\%) and silent (14\%) perforation [50], and as long term palliation where perforation, and migration, have also been reported; bevacizumab therapy increases the risk of perforation in these cases [51].

\section{Variceal ligation/sclerosis}

The overall AEs from endoscopic variceal sclerotherapy (EVS) have been estimated between 35\% and $78 \%$, with a mortality rate of 1-5\% [52]. Significant immediate and delayed bleeding, stricture 
formation, perforation, systemic bacterial infection, or even portal thrombosis, were reported [53]. However, endoscopic band ligation (EBL) was progressively considered the treatment of choice, with significant lower rates of AEs [54,55]. Effective endoscopic treatment for gastric varices is still a sclerosant, properly the cyanoacrylate. Although considered relatively safe and effective, it is associated with systemic embolization, end-organ infarction, visceral fistula, abscess formation and bacteraemia $[23,24]$. Recent studies highlight only $1 \%$ rate of severe complications, as embolization [56]. It seems that the severity of AEs is related to pre-existing liver condition and infections complications [57].

Percutaneous endoscopic gastric and jejunal (PEG/PEJ) access

Serious AEs occur in 1.5 to 9.4\% of PEG procedures and include bleeding, injury of internal organs, perforation, 'buried bumper syndrome', wound infection, and necrotizing fasciitis [58]. Peristomal wound infections occur in $7-47 \%$ of patients receiving placebo in clinical trials, a single dose of cephalosporin or penicillin-based prophylaxis resulted in a significant reduction [59]. Pneumoperitoneum is a benign and frequent occurrence. Bleeding from gastric or abdominal wall vessels is reported in less than $1 \%$ of procedures, it is important to reverse or held anticoagulants before. Prevention of injury to internal organs may be best achieved by ensuring adequate transillumination and finger indentation, and by use of the 'safe-tract' technique. AEs associated with PEJ are similar to those of standard PEG placement, although their rate is higher [60].

\section{Ablation techniques}

Argon plasma coagulation (APC) is frequently used to treat vascular ectasia or for mucosal lesions ablation, as Barrett's oesophagus. Randomized trials report up to $4 \%$ of bleeding, $2 \%$ of oesophageal perforation and $6 \%$ of stricture formation in oesophagus [61]. Colonic use of APC, can be associated with a rare but dreaded event - colon explosion - that may lead to perforation and emergency surgery. Meticulous full bowel cleansing with preparation without sugar compounds should be carried out before any APC in the colon [62].

Radiofrequency ablation (RFA) of Barrett's epithelium has a relatively favourable profile. Bleeding requiring endoscopic therapy occur in less than $2 \%$ and strictures in $2-8 \%$, perforation has also been reported $[63,64]$.

\section{Endoscopic submucosal tunnelling procedures}

Peroral endoscopic myotomy (POEM) and subepithelial lesions resection

Common described complications include subcutaneous and mediastinal emphysema, pneumothorax, pneumoperitoneum, immediate or delayed haemorrhage, and infection. Caution should be taken when implementing these techniques. There are no specific recommendations until now $[65,66]$.

\section{Enteroscopy}

Enteroscopy using double-balloon (DBE), single-balloon or spiral enteroscopy have the potential for unique AEs. A meta-analysis of 9047 DBE found major AEs in $0.7 \%$ (perforation, pancreatitis, bleeding) [67]. The mechanisms of pancreatitis remain poorly understood, and the main way to prevent it is avoiding balloon inflation at duodenal level. The AEs rate is higher for therapeutic (4.3\%) than for diagnostic DBE $(0.8 \%)$. The rate of bleeding or perforation may be as high as $10.8 \%$ for patients undergoing polypectomy during DBE $[67,68]$.

\section{Endoscopic retrograde cholangiopancreatography (ERCP)}

ERCP is a demanding procedure associated with significant morbidity (6.85\% of AEs) and occasional mortality (0.33\%) [69-71]. AEs can be divided into general (in common with upper GI endoscopy) and specifically related to bilio-pancreatic handling (bleeding, perforation, infection 
and pancreatitis). Factors modulating the risk of complications are the indication for ERCP and type of intervention, case-volume of operator, age and co-morbidities of the patient [72]. Pancreatitis is the most prevalent cause of morbidity and mortality after ERCP, but it will not be discussed in this issue.

Bleeding is mainly linked to sphincterotomy and in half of the cases is recognized immediately [69]. Clinically significant haemorrhage occurs in $0.1 \%-2 \%$ of sphincterotomies. It can be attenuated by identifying patients at risk and adapting the sphincterotomy technique-limiting pure-cut current, using endocut mode or balloon sphincteroplasty, according to situations.

Perforation occurs in $0.6 \%$ of procedures, with an estimated mortality rate of $0.06 \%$ [69], however delayed diagnosis and intervention increase mortality up to $23 \%$. The most commonly used classification of ERCP-induced perforation was suggested by Stapfer et al according to that, perforations can be categorized into four types. Bowel perforation is more frequent in patients with Billroth II gastrectomy or Roux-en-Y operation, duodenal stricture, parapapillar diverticulum, while sphincterotomy perforation is more common during needle knife precut $[25,73]$. It can be prevented by ensuring the correct orientation of the cutting wire during sphincterectomy, following a step-by-step incision, tailoring the size of the papilla and bile ducts, and using balloon dilation of the papilla after a small sphincterotomy in cases of large stones [5].

Cholangitis and cholecystitis are potential infectious AEs. Risk factors for cholangitis are failed or incomplete biliary drainage or combined percutaneous-endoscopic procedures [70]. Prophylactic antibiotics can reduce the rate of bacteraemia but few studies showed a reduction in clinical sepsis [74]. Therefore the main recommendation regarding prevention and treatment of cholangitis is successful and complete biliary drainage. Post-ERCP acute cholecystitis has an incidence rate of $<0.5 \%$ and can be related to the non-sterile introduction of contrast medium. The use of cleaned and disinfected scopes, sterile contrast medium and temporary bile duct drainage when definitive drainage cannot be achieved are required. Antibiotic prophylaxis has proven to be effective in patients at risk for infective endocarditis, in patients with pancreatic pseudocyst and in patients with cholestasis or enlarged bile ducts [5].

ERCP-induced air embolism is a rare but severe complication [25] that possibly occurs due to sphincterotomy or high intra-mural pressure of insufflated air, disrupting the gastrointestinal or hepatobiliary structure and creating connection to the veins in the duodenal walls. Other reported mechanisms include portal vein puncture due to guide-wire cannulation and erroneous placement of nasobiliary drainage tube to the portal vein $[75,76]$. Special care should be taken for possible air embolism in relation to the recent wide application of peroral cholangioscopy [77]. Other potential very rare complications are splenic injury, hepatic haematoma, pneumothorax and basket impactation [25].

\section{Endoscopic ultrasound (EUS)}

The non-interventional diagnostic EUS AEs rate of $0.03 \%$ to $0.15 \%$ is comparable to that of upper GI diagnostic endoscopy. Although due to specific mechanical and optical properties of echoendoscopes, the risk of oesophageal or duodenal perforation seems somewhat higher. Patients undergoing EUS-fine needle biopsy (EUS-FNB) are approximately ten times more likely to develop AEs [78]. In a recent systematic review the overall complication rate and mortality was $0.98 \%$ and $0.02 \%$ respectively. Significant AEs were acute pancreatitis (34\%), fever and infectious complications (16\%), bleeding (13\%) and perforation or bile/pancreatic leaks (3\%). Serious infections were described in published reports following biopsy of mediastinal lymph nodes, cystic lesions, ascitis or pleural fluid [78]. Antibiotic prophylaxis should be administered in patients undergoing EUS-FNB of cystic lesions and fluid collections [79]. Self-limited mild intraluminal bleeding was reported in up to $4 \%$ and extraluminal bleeding in $1.3 \%$ of cases, the last can be visualized clearly by EUS [80]. Patients with highly vascularized lesions (mesenchymal, neuroendocrine tumours, and some metastases) and cystic lesions may be at greater risk [78]. According to guidelines, EUS-FNB of solid masses and lymph nodes may be performed in patients taking acetyl salicylic acid (ASA) or NSAIDs, but not in patients receiving other anticoagulant or antiaggregant drugs. However, EUS-FNB of cystic lesions should be avoided in patients taking any antiplatelet agent $[28,81]$. 
At this moment, EUS is an increasing reference for a range of therapeutic procedures with specific complications risk, as drainage of pancreatic pseudocysts, abscess and necrosis debridement [82,83], celiac plexus neurolysis [84], biliary drainage [85], or even research vascular procedures [86].

\section{Detection and management of the two main emergencies}

\section{Haemorrhage}

Bleeding during therapeutic endoscopy can be a part of the procedure, especially during polypectomies, EMR or ESD [5]. Immediate and late bleeding (by definition is haematemesis and/or melena or haemoglobin drop $>2 \mathrm{~g}$ ) [1] can be controlled with conventional haemostatic tools (Fig. 1), under simultaneous attention to resuscitation and conservative management. Reader is referred to the chapter of acute non-variceal bleeding in this volume.

Patients with upper GI resection of tumoral lesions should be treated with intravenous PPI as for Forrest IIa ulcers [5]: High-dose PPI therapy improves healing rates and reduces the risk of delayed bleeding [33]. There are small successful series of over-the-scope-clips (OTSC) use in acute GI bleeding unresponsive to conventional methods, which is becoming a consistent approach [87]. The hemospray, a highly absortive powder that when in contact with blood becomes cohesive and forms a stable mechanical plug, is also a promising haemostatic agent as demonstrated in early studies [88].

Also in post-sphincterotomy bleeding, the first line treatment is injection of dilute epinephrine. Balloon-tamponade using standard dilating balloons for temporary control of bleeding and improve visualization of the bleeding point. Thermal therapy or placement of clips can follow the initial measures. Caution should be taken to avoid thermal injury or clip closure over the pancreatic sphincter [74]. Self-expandable metal stents have also been used as a rescue technique if other methods fail [89]. Very rarely, angiography or surgery is required for refractory bleeding.

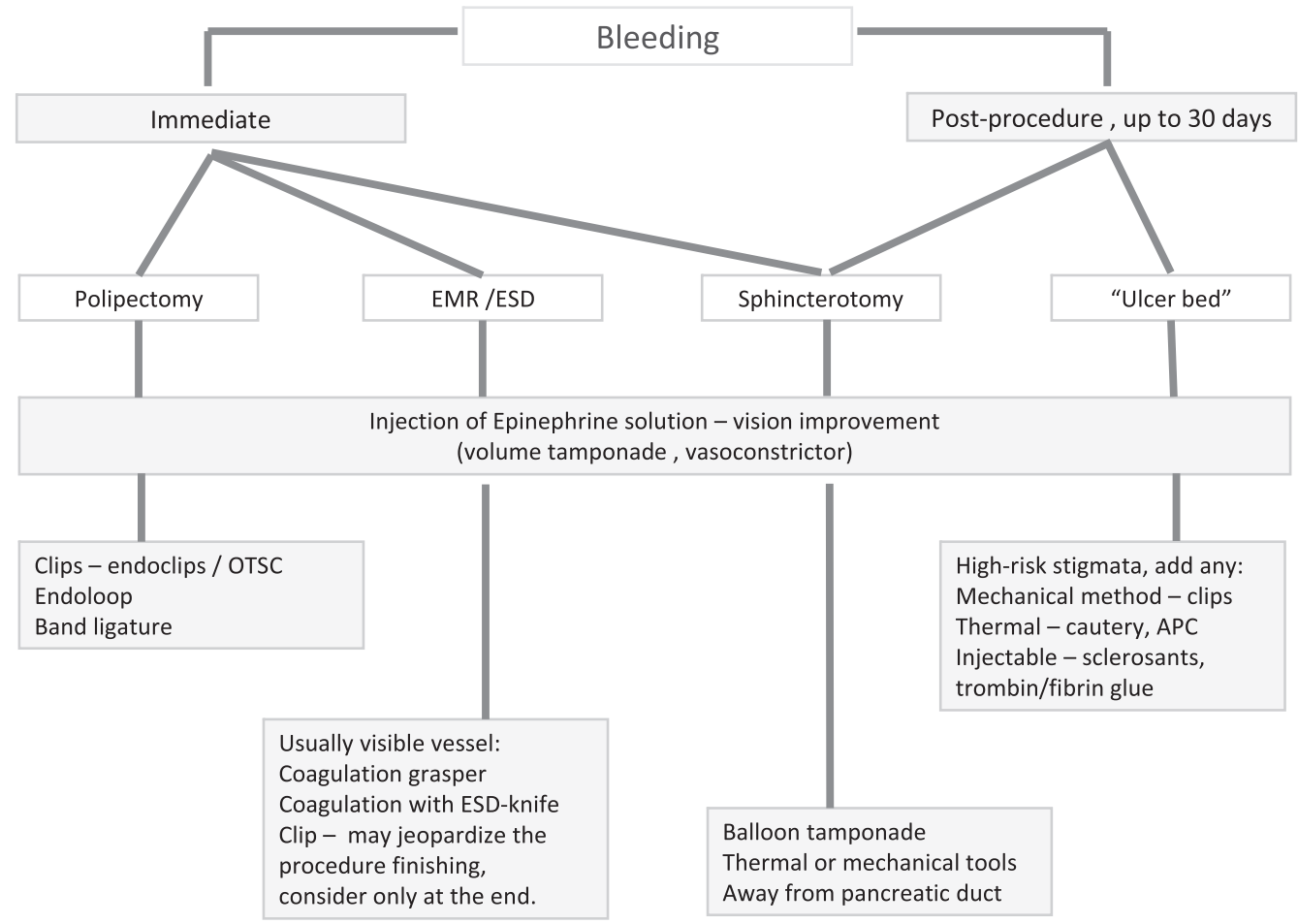

Fig. 1. Management of post-endoscopic procedures' bleeding. 


\section{Perforation}

Luminal perforation still is the most feared AEs of GI endoscopy, even after some advances and demystification brought by natural orifices transluminal endoscopic surgery (NOTES). The rationale for that is multifactorial $[1,90]$. A recent review by Baron et al pointed out some main commandments of acute endoscopic perforation: (1) prompt recognition (preferably during the procedure) is essential to improve outcome; (2) extraluminal air does not automatically mean the need for surgery as it is not infectious and is not necessarily proportional to the size of the perforation; (3) extraluminal air under pressure is a medical emergency; (4) residual extraluminal air may persist without clinical significance; (5) perforations tend to close after drainage or diversion of luminal contents; (6) failed endoscopic closure generally requires surgical intervention.

\section{General approach}

In therapeutic procedures, it is very important a final careful examination, in this case diagnosis or suspicious is frequently immediate and allows prompt closure attempt. In certain circumstances symptoms may be masked, as in sedated or elderly patients with multiple co-morbidities, small perforations, or in case of transmural burn syndrome with progressive wall fragility. Whenever there is a clinical deterioration hours after an endoscopic procedure, delayed perforation should be considered. Late recognition may be from one hour to several weeks later. Clinical suspicious should be heightened in the presence of ongoing abdominal distension/pain, chest pain, shortness of breath, subcutaneous emphysema or fever [91]. Once suspected, besides closure attempt, immediate general measures should take place, as administration of intravenous broad-spectrum antibiotics, vital signs monitorization, blood tests, surgeon contact and counselling, placement of a nasogastric tube (except in oesophageal perforation, because it may exit the perforated site), and cessation of oral intake. At the same time, if periprocedure perforation, switch as much as possible to $\mathrm{CO}_{2}$ insufflation. If perforation is suspected later, an initial imaging assessment should include a chest and flat/upright abdominal radiography, if unrevealing computerized tomography CT with water-soluble contrast (orally, via nasogastric or nasoduodenal tube, or per rectum) may show contained or free contrast material extravasation. Endoscopic closure should then be attempted if feasible (Figs. 2 and 3 ) $[5,90,92]$.

An essential and lifesaving attitude is emergent decompression when extraluminal air is under pressure. Tension pneumothorax requires immediate needle catheter inserted along the midclavicular line in the second intercostal space of the affected side. Then a chest tube should be placed. Subcutaneous emphysema usually resolve spontaneously, however attention should be given when massive air is tracking into soft tissues of the neck as it can result in airway obstruction, needing endotracheal intubation. Avoid abdominal compartment syndrome (drop in blood-pressure levels, related to a decreased cardiac preload caused by peritoneal hypertension) in tension pneumoperitoneum, with a 18 or 20 gauge trocar needle in either lower abdominal quadrants, just at or inferior to the umbilicus. The needle should be removed but the plastic sheath is left in situ to allow continuous decompression of the peritoneal cavity, while the procedure resumes and endoscopic intervention is ongoing even under air insufflation (Fig. 4) [5,90,93].

\section{Endoscopic closure methods}

Endoscopic closure methods include clips, stents and suturing devices. Its selection relies on defect location, dimension and conformation, occurrence situation, equipment availability and operator preference. Through-the-scope endoclips (QuickClip - Olympus ${ }^{\circledR}$, Resolution Clip - Boston Scientific ${ }^{\circledR}$, Tri-clip - Cook Medical ${ }^{\circledR}$ ) are the most used and currently the standard method for endoscopic closure of perforations [94]. It has been suggested that for defects smaller than the width of the open clip it should be clipped in a 'side to center' manner; when the defect is slightly larger than the width of the open clip, the diameter can be reduced by air suction. In case of large defects, the first clip is the most critical and a recent proposal for certain cases is to perform small incisions around to provide a better grip for the clip [95]. Combined methods are also a good approach for larger defects, for instances, hemoclips plus Endoloop [96,97], plus omental patch [93] or plus band ligation [98]. OTSC system, initially developed for haemostasis, but extensively explored for 'otomies' closure in NOTES [99] are 


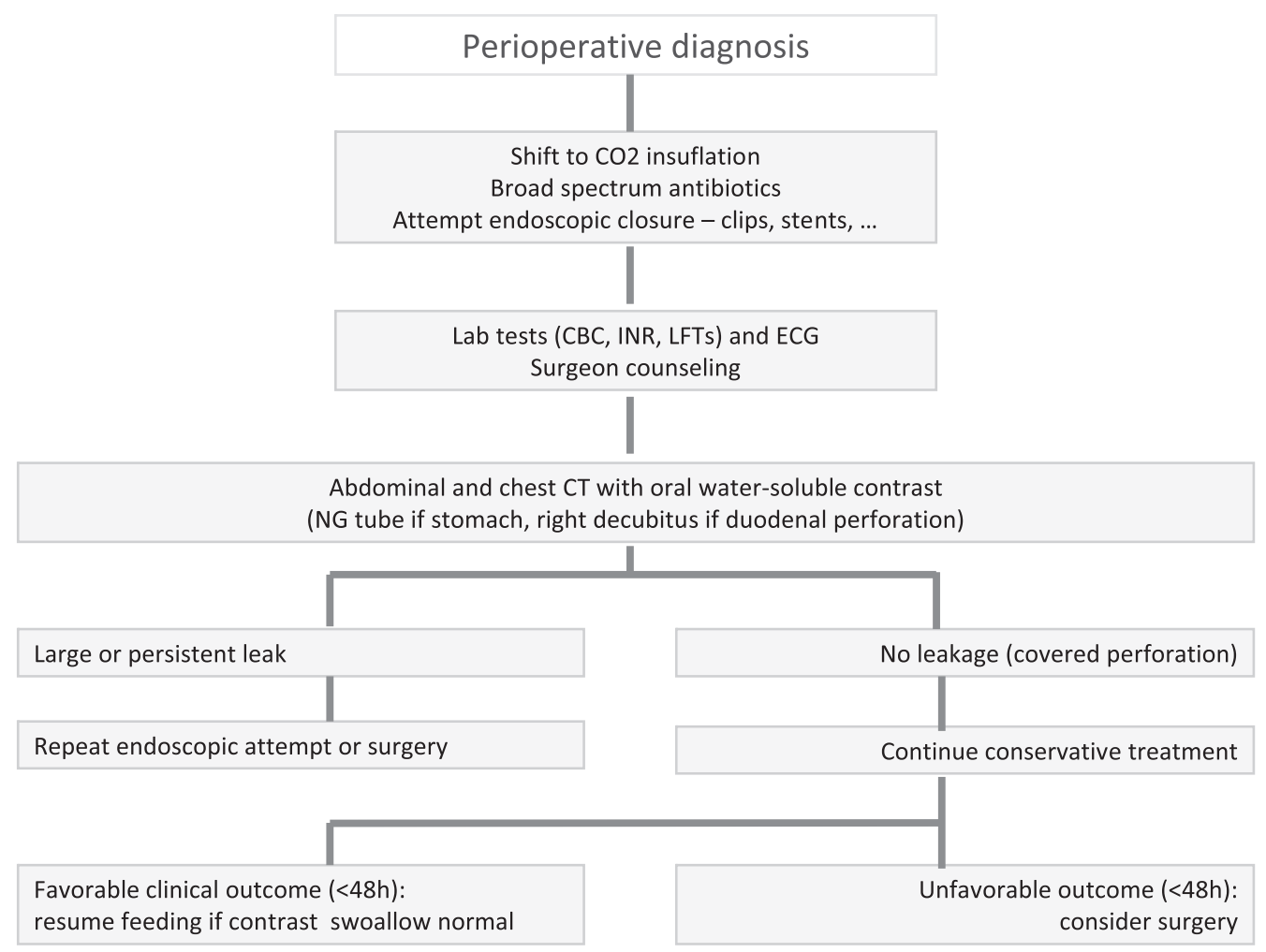

Fig. 2. Management of upper GI perforations. Adapted from Blero D, Devière J. Nat Rev Gastroenterol Hepatol. 2012.

ultimately applied in perforation's closure, using or not specific grasping or anchoring devices to approximate margins before clip release. Stents are an alternative method (fully or partially covered metal stents and plastic stents) for luminal diversion, mainly in oesophageal malignant rupture. Stents can also be used in benign perforation, and removed 4-12 weeks later. Several endoscopic suturing prototypes were developed in the context of NOTES, anti-reflux and bariatric procedures $[90,100]$ namely: T-tags (Ethicon Endo-Surgery and Cook Endoscopy), Overstitch (Apollo Endosurgery), pursed-string-suturing device (LSI Solutions), flexible endostitch (Covidien), NDO plicator (NDOSurgicalInc), flexible stapler (Power Medical Interventions), nevertheless its application remains limited in humans, and some of them only tested in animal models.

\section{Location particularities}

In oesophagus, non-surgical treatment is indicated only in highly well selected [101]. Primary repair is feasible if without intrinsic oesophageal disease, absence of sepsis, and especially when the time

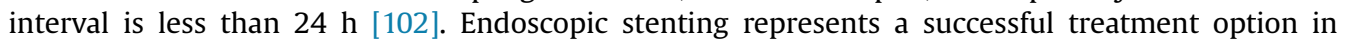
perforated non-resectable oesophageal malignancy. In cases of benign rupture, the stent placement for a period of 5-6 weeks is effective in 76\% of patients, with no significant difference between stents [103]. Nevertheless, complication rate can be as high as $20-72 \%$, thus the stent choice should depend on expected risk of stent migration (mostly with fully covered SEMSs, and less frequent in presence of any stricture) and to a minor degree, on expected risk of tissue in- or overgrowth (mostly with partially covered SMESs). In this situation a fully covered stent of the same diameter can be placed inside (stentin-stent method) allowing uneventful removal of both after 10-14 days. This can also be precluded with the initial application of large diameters fully covered stents (22-23 in the body) [103]. Finally, standard through-the-scope clips are successful in the closure of perforations up to $12 \mathrm{~mm}$, in a pooled 


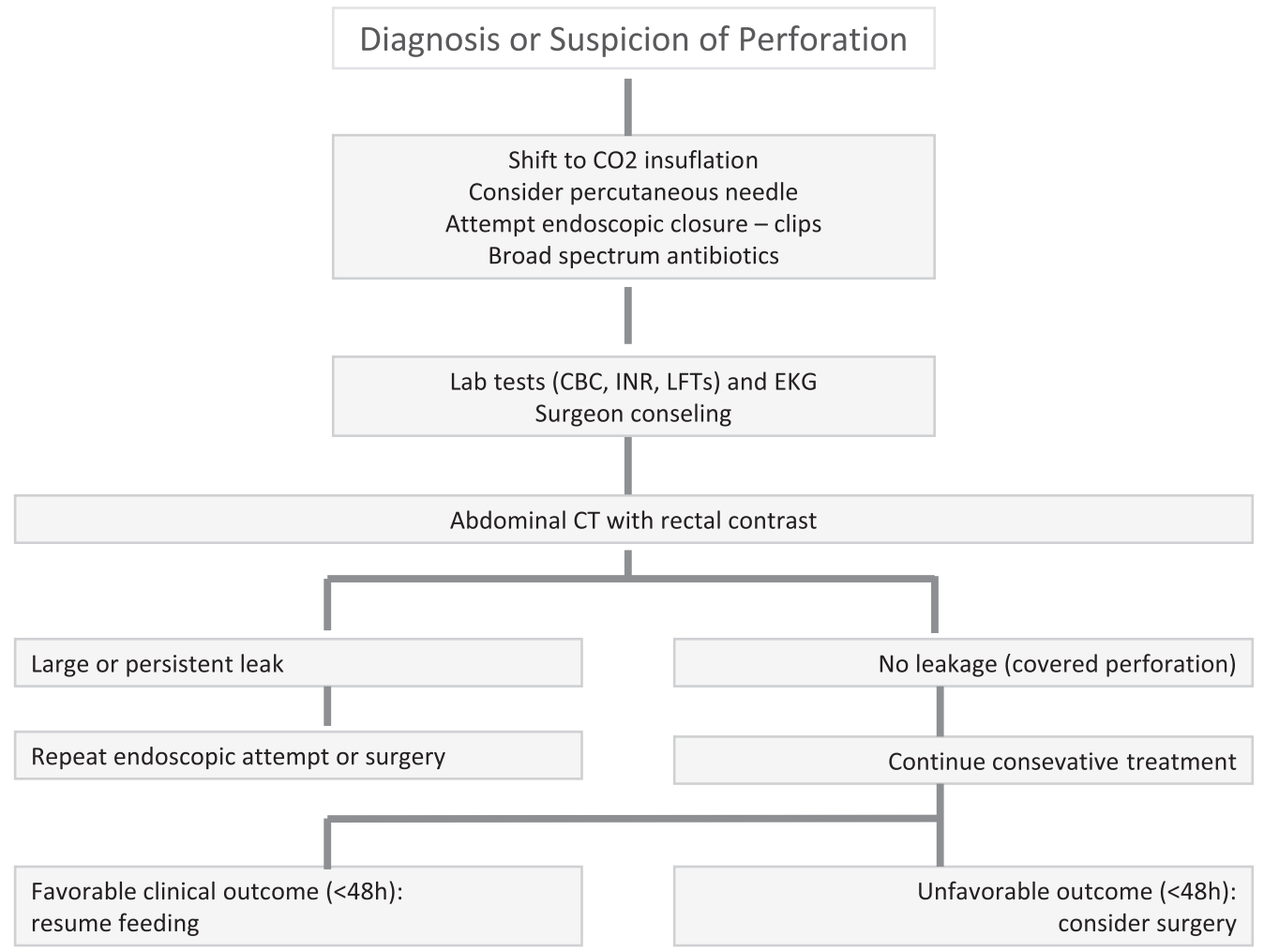

Fig. 3. Management of lower GI perforations. Adapted from Blero D, Devière J. Nat Rev Gastroenterol Hepatol. 2012.

analysis where the median healing time was 18 days [104]. Vacuum-assisted therapy is also a possible technique [105]. OTSC brings technical difficulties in oesophageal application because of narrow lumen and oblique orientation [106].

In gastric perforations, the main closure approach is endoclipping alone or in combination, which can achieve $98 \%$ of success if immediate diagnosis [93]. Shi et al described a new combination technique of metallic clips and endoloops as interrupted suture after endoscopic full-thickness resection of gastric submucosal tumours in 20 patients [97]; when the defect is large (25 $\mathrm{mm}$ ) it can as well be managed by the omental-patch method or the OTSC system $[93,106]$.

In ERCP-related duodenal perforations, different approaches are made according to the type and the severity of the leak and clinical manifestations [107]. In type I and type II perforations, surgical treatment was generally recommended, although recent successful reports of endoscopic closure with endoclips [108], combined clips and endoloops or OTSC were published [109]; particularly in type II perforations, self-expandable metal stents seems to be effective [110]. Type III and IV perforations tend to be a controlled retroperitoneal perforation; in case of leak with fluid collection, the recognizing and quick plastic stents placing for appropriate drainage, associated with antibiotics are essential [107]. In retroperitoneal perforations, $87.9 \%$ of patients recovered with conservative treatment (total mortality was $2.9 \%$ ), and $80.8 \%$ of patients with free air peritoneal perforations received surgery (total mortality was $24.7 \%)$.

Small bowel enteroscopy related perforations often lead to surgical management.

In colon perforations, endoscopic closure in association with conservative management is successful in $60-100 \%$ of patients, avoiding the morbidity of surgery and shortening the length of hospital stay, provided that perforation is immediately recognized and closed. Initial series showed success with 

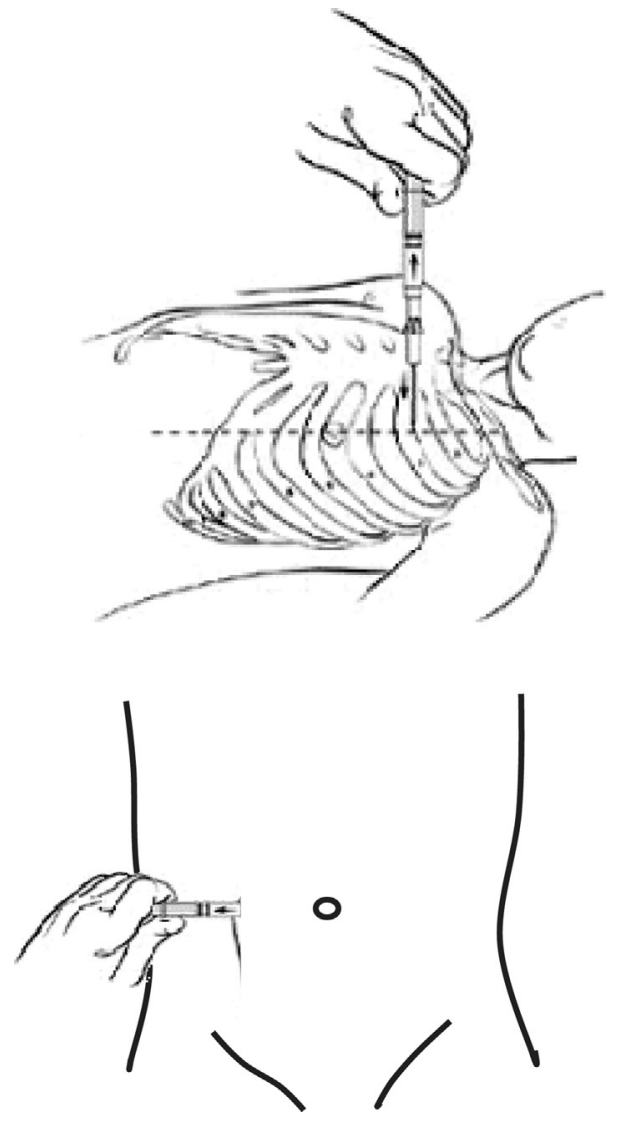

Fig. 4. Acute decompression of tension pneumothorax and pneumoperitoneum.

endoclips for small perforations [111,112], in the absence of peritoneal irritation. Subsequently also diagnostic, large perforations, in the presence of free air or moderately inflammatory signs, were also successfully treated with multiple clipping, OTSC or even band ligation [90]. Bowel preparation status is in general an important factor that may influence clinical management. In delayed recognition, clipping should be considered only if the patient is stable and a specific site is highly suspected, mainly in rectosigmoid location [112]. When comparing diagnostic and therapeutic colonoscopy-associated perforation, the former is usually larger, irregular and sometimes not immediately recognized in terms of location, thus it is more prompt for surgical approach [113]. Surgery is indicated in patients with large perforations, generalized peritonitis or ongoing sepsis as well as in patients with concomitant pathology, such as a large sessile polyp likely to be a carcinoma, unremitting colitis, or obstructing colonic lesion. Although rare, extraperitoneal colonic perforation (subcutaneous emphysema, pneumoretroperitoneum, pneumomediastinum, pneumopericardium) should be managed conservatively, and the air is commonly reabsorbed within $72 \mathrm{~h}$ [114]. In rectum, located below the peritoneal reflection air leakage can develop through next or distal soft tissues. Penetration to perirectal tissue is a better designation and is treated with broad-spectrum antibiotics and nothing by mouth even though endoscopic clips can also be applied [90].

In all these cases a coordinated surveillance by the surgical and medical team is essential in the first $48 \mathrm{~h}$. In case of no improvement or any sign of deterioration, surgery should be considered in a case-bycase decision. 


\section{Conclusion}

Endoscopic complications are a pertinent feature of patient care that has been receiving great attention, due to increased technical advances and complexity of therapeutic endoscopy. Three main factors contribute to endoscopic adverse events - patient, operator, and type of procedure. Thus a comprehensive knowledge of the techniques and materials, experience acquisition and maintenance in specific procedures, standardization of treatments and training are important issues for prevention of AEs. When facing an AE, early recognition and prompt approach by endoscopic or multidisciplinary management, are essential for a successful outcome. No rule suits all, hence endoscopic complication approach must be customized to individual patients.

\section{Practice points}

- Adverse event $(\mathrm{AE})$ is a situation that prevents completion of the planned procedure.

- Be prepared for the endoscopic procedure and furthermore its possible AEs - theoretical knowledge, equipment, team, and environment conditions.

- According to indications prevent infection and bleeding risk.

- Early recognition is a determining factor of the general outcome results.

- Bleeding (early and delayed) is usually controlled by endoscopic haemostasis.

- In perforation, an endoscopic plus conservative treatment, under multidisciplinary surveillance should always be attempted, if possible.

- Emergent needle decompression is an essential and lifesaving attitude when extraluminal air is under tension.

- Review AEs as part of continuing quality improvement.

\section{Research agenda}

- Multicenter studies to define associated risk factors of AEs for each newly-introduced procedure.

- Comparative studies between the newly appearing tools for haemostasis and closure.

- Effective, user-friendly and cheaper suture devices for endoscopy.

- Safer tools for endoluminal dissection (knifes and coagulation graspers).

- Increment biodegradable tools - protective plug, spray and stents.

- Image fusion systems for safer approach in more aggressive procedures.

\section{Disclosure statement}

Regarding this manuscript - 'EMERGENCIES AFTER ENDOSCOPIC PROCEDURES' - none of the authors (Carla Rolanda, Ana C. Caetano e Mário Dinis-Ribeiro) have any disclosures to make.

\section{References}

[1] Cotton PB, Eisen GM, Aabakken L, Baron TH, Hutter MM, Jacobson BC, et al. A lexicon for endoscopic adverse events: report of an ASGE workshop. Gastrointest Endosc 2010;71(3):446-54.

[2] Cotton PB, Eisen G, Romagnuolo J, Vargo J, Baron T, Tarnasky P, et al. Grading the complexity of endoscopic procedures: results of an ASGE working party. Gastrointest Endosc 2011;73(5):868-974. http://www.ncbi.nlm.nih.gov/pubmed? term=Jacobson\%20B\%5BAuthor\%5D\%26cauthor=true\%26cauthor_uid=21377673.

[3] ASGE Standards of Practice Committee. Adverse events of upper GI endoscopy. Gastrointest Endosc 2012;76(4):707-18.

[4] Sharma VK, Nguyen CC, Crowell MD, Lieberman DA, de Garmo P, Fleischer DE. A national study of cardiopulmonary unplanned events after GI endoscopy. Gastrointest Endosc 2007 Jul;66(1):27-34.

[5] Blero D, Devière J. Endoscopic complications - avoidance and management. Nat Rev Gastroenterol Hepatol 2012;9(3):162-72.

[6] Bowles CJ, Leicester R, Romaya C, Swarbrick E, Williams CB, Epstein O. A prospective study of colonoscopy practice in the UK today: are we adequately prepared for national colorectal cancer screening tomorrow? Gut 2004;53(2):277-83. 
[7] Montalvo RD, Lee M. Retrospective analysis of iatrogenic Mallory-Weiss tears occurring during upper gastrointestinal endoscopy. Hepatogastroenterology 1996;43(7):174-7.

[8] Van Os EC, Kamath PS, Gostout C], Heit JA. Gastroenterological procedures among patients with disorders of hemostasis: evaluation and management recommendations. Gastrointest Endosc 1999;50(4):536-43.

[9] Quine MA, Bell GD, McCloy RF, Charlton JE, Devlin HB, Hopkins A. Prospective audit of upper gastrointestinal endoscopy in two regions of England: safety, staffing, and sedation methods. Gut 1995;36(3):462-7.

[10] Straumann A, Bussmann C, Zuber M, Vannini S, Simon HU, Schoepfer A. Eosinophilic esophagitis: analysis of food impaction and perforation in 251 adolescent and adult patients. Clin Gastroenterol Hepatol 2008;6(5):598-600.

[11] Vogel SB, Rout WR, Martin TD, Abbitt PL. Esophageal perforation in adults: aggressive, conservative treatment lowers morbidity and mortality. Ann Surg 2005;241(6):1016-21.

[12] Abbas G, Schuchert MJ, Pettiford BL, Pennathur A, Landreneau J, Landreneau J, et al. Contemporaneous management of esophageal perforation. Surgery 2009;146(4):749-55.

[13] Lohsiriwat V. Colonoscopic perforation: incidence, risk factors, management and outcome. World J Gastroenterol 2010; 16(4):425-30.

[14] Yoshida N, Yagi N, Naito Y, Yoshikawa T. Safe procedure in endoscopic submucosal dissection for colorectal tumors focused on preventing complications. World J Gastroenterol 2010;16(14):1688-95.

[15] Stock C, Ihle P, Sieg A, Schubert I, Hoffmeister M, Brenner H. Adverse events requiring hospitalization within 30 days after outpatient screening and nonscreening colonoscopies. Gastrointest Endosc 2013;77(3):419-29.

[16] Tam MS, Abbas MA. Perforation following colorectal endoscopy: what happens beyond the endoscopy suite? Perm J 2013;17(2):17-21.

[17] Garbay JR, Suc B, Rotman N, Fourtanier G, Escat J. Multicentre study of surgical complications of colonoscopy. Br J Surg 1996;83(1):42-4.

[18] ASGE Quality Assurance in Endoscopy Committee. Multisociety guideline on reprocessing flexible gastrointestinal endoscopes: 2011. Gastrointest Endosc 2011;73(6):1075-84.

[19] Nelson DB. Infectious disease complications of GI endoscopy: part II, exogenous infections. Gastrointest Endosc 2003; 57(6):695-711.

[20] Nelson DB. Infectious disease complications of GI endoscopy: part I, endogenous infections. Gastrointest Endosc 2003; 57(4):546-56.

[21] Endoscopy Committee of the British Society of Gastroenterology. Antibiotic prophylaxis in gastrointestinal endoscopy. Gut 2009;58(6):869-80.

[22] Deboever G, Elegeert I, Defloor E. Portal and mesenteric venous thrombosis after endoscopic injection sclerotherapy. Am J Gastroenterol 1989;84(10):1336-7.

[23] Alexander S, Korman MG, Sievert W. Cyanoacrylate in the treatment of gastric varices complicated by multiple pulmonary emboli. Intern Med J 2006;36(7):462-5.

[24] Neumann H, Scheidbach H, Mönkemüller K, Pech M, Malfertheiner P. Multiple cyanoacrylate (Histoacryl) emboli after injection therapy of cardiavarices. Gastrointest Endosc 2009;70(5):1025-6.

[25] Kwon CI, Song SH, Hahm KB, Ko KH. Unusual complications related to endoscopic retrograde cholangiopancreatography and its endoscopic treatment. Clin Endosc 2013;46(3):251-9.

[26] Lépilliez V, Chemaly M, Ponchon T, Napoleon B, Saurin JC. Endoscopic resection of sporadic duodenal adenomas: an efficient technique with a substantial risk of delayed bleeding. Endoscopy 2008;40(10):806-10.

[27] Sorbi D, Norton I, Conio M, Balm R, Zinsmeister A, Gostout CJ. Postpolypectomy lower GI bleeding: descriptive analysis. Gastrointest Endosc 2000;51(6):690-6.

[28] Boustière C, Veitch A, Vanbiervliet G, Bulois P, Deprez P, Laquiere A, et al. Endoscopy and antiplatelet agents. European Society of Gastrointestinal Endoscopy (ESGE) guideline. Endoscopy 2011;43(5):445-61. http://www.ncbi.nlm.nih.gov/ pubmed?term=Lesur\%20G\%5BAuthor\%5D\%26cauthor=true\%26cauthor_uid=21547880.

[29] Cao Y, Liao C, Tan A, Gao Y, Mo Z, Gao F. Meta-analysis of endoscopic submucosal dissection versus endoscopic mucosal resection for tumors of the gastrointestinal tract. Endoscopy 2009;41(9):751-7.

[30] Apel D, Jakobs R, Spiethoff A, Riemann JF. Follow-up after endoscopic snare resection of duodenal adenomas. Endoscopy 2005;37(5):444-8.

[31] Dinis-Ribeiro M, Pimentel-Nunes P. Should antiplatelets be stopped before gastric mucosectomy? For how long and in whom? Endoscopy 2012 Feb;44(2):111-3.

[32] Dinis-Ribeiro M, Pimentel-Nunes P, Afonso M, Costa N, Lopes C, Moreira-Dias L. A European case series of endoscopic submucosal dissection for gastric superficial lesions. Gastrointest Endosc 2009;69(2):350-5.

[33] Kakushima N, Fujishiro M. Endoscopic submucosal dissection for gastrointestinal neoplasms. World J Gastroenterol 2008;14(19):2962-7.

[34] Tamiya Y, Nakahara K, Kominato K, Serikawa O, Watanabe Y, Tateishi H, et al. Pneumomediastinum is a frequent but minor complication during esophageal endoscopic submucosal dissection. Endoscopy 2010;42(1):8-14.

[35] Saito Y, Otake Y, Sakamoto T, Nakajima T, Yamada M, Haruyama S, et al. Indications for and technical aspects of colorectal endoscopic submucosal dissection. Gut Liver 2013;7(3):263-9. http://www.ncbi.nlm.nih.gov/pubmed?term=Abe\%20S\% 5BAuthor\%5D\%26cauthor=true\%26cauthor_uid=23710305.

[36] Kobayashi N, Yoshitake N, Hirahara Y, Konishi J, Saito Y, Matsuda T, et al. Matched case-control study comparing endoscopic submucosal dissection and endoscopic mucosal resection for colorectal tumors. J Gastroenterol Hepatol 2012;27(4):728-33.

[37] Piotet E, Escher A, Monnier P. Esophageal and pharyngeal strictures: report on 1,862 endoscopic dilatations using the Savary-Gilliard technique. Eur Arch Otorhinolaryngol 2008;265(3):357-64.

[38] Nelson DB, Sanderson SJ, Azar MM. Bacteremia with esophageal dilation. Gastrointest Endosc 1998;48(6):563-7.

[39] Hernandez LV, Jacobson JW, Harris MS. Comparison among the perforation rates of Maloney, balloon, and savary dilation of esophageal strictures. Gastrointest Endosc 2000;51:460-2.

[40] Jacobs Jr JW, Spechler SJ. A systematic review of the risk of perforation during esophageal dilation for patients with eosinophilic esophagitis. Dig Dis Sci 2010;55(6):1512-5. 
[41] Boeckxstaens GE, Annese V, des Varannes SB, ChaussadeS, Costantini M, Cuttitta A, et al., European Achalasia Trial Investigators. Pneumatic dilation versus laparoscopic Heller's myotomy for idiopathic achalasia. N Engl J Med 2011;364(19):1807-16.

[42] Fukami N, Anderson MA, Khan K, Harrison ME, Appalaneni V, Ben-Menachem T, et al. The role of endoscopy in gastroduodenal obstruction and gastroparesis. Gastrointest Endosc 2011;74(1):13-21. http://www.ncbi.nlm.nih.gov/ pubmed?term=Fanelli\%20RD\%5BAuthor\%5D\%26cauthor=true\%26cauthor_uid=21704805.

[43] Stienecker K, Gleichmann D, Neumayer U, Glaser HJ, Tonus C. Long-term results of endoscopic balloon dilatation of lower gastrointestinal tract strictures in Crohn's disease: a prospective study. World J Gastroenterol 2009;15(21):2623-7.

[44] Hassan C, Zullo A, De Francesco V, Lerardi E, Giustini M, Pitidis A, et al. Systematic review: endoscopic dilatation in Crohn's disease. Aliment Pharmacol Ther 2007;26(11-12):1457-64. http://www.ncbi.nlm.nih.gov/pubmed?term=Winn \%20S\%5BAuthor\%5D\%26cauthor=true\%26cauthor_uid=17903236.

[45] Sgourakis G, Gockel I, Radtke A, Dedemadi G, Goumas K, Mylona S, et al. The use of self-expanding stents in esophageal and gastroesophageal junction cancer palliation: a meta-analysis and meta-regression analysis of outcomes. Dig Dis Sci 2010;55(11):3018-30. http://www.ncbi.nlm.nih.gov/pubmed?term=Tsiamis\%20A\%5BAuthor\%5D\%26cauthor=true\% 26cauthor_uid=20440646.

[46] Baron TH. Minimizing endoscopic complications: endoluminal stents. Gastrointest Endosc Clin N Am 2007;17(1):83-104.

[47] Verschuur EM, Steyerberg EW, Kuipers EJ, Siersema PD. Effect of stent size on complications and recurrent dysphagia in patients with esophageal or gastric cardia cancer. Gastrointest Endosc 2007;65(4):592-601.

[48] Gaidos JK, Draganov PV. Treatment of malignant gastric outlet obstruction with endoscopically placed self-expandable metal stents. World J Gastroenterol 2009;15(35):4365-71.

[49] Maetani I, Ukita T, Tada T, Shigoka H, Omuta S, Endo T. Metallic stents for gastric outlet obstruction: reintervention rate is lower with uncovered versus covered stents, despite similar outcomes. Gastrointest Endosc 2009;69(4):806-12.

[50] Tan CJ, Dasari BV, Gardiner K. Systematic review and meta-analysis of randomized clinical trials of self-expanding metallic stents as a bridge to surgery versus emergency surgery for malignant left-sided large bowel obstruction. $\mathrm{Br} \mathrm{J}$ Surg 2012;99(4):469-76.

[51] Bonin EA, Baron TH. Update on the indications and use of colonic stents. Curr Gastroenterol Rep 2010;12(5):374-82.

[52] Schuman BM, Beckman JW, Tedesco FJ, Griffin Jr JW, Assad RT. Complications of endoscopic injection sclerotherapy: a review. Am J Gastroenterol 1987;82(9):823-30.

[53] Yuki M, Kazumori H, Yamamoto S, Shizuku T, Kinoshita Y. Prognosis following endoscopic injection sclerotherapy for esophageal varices in adults: 20-year follow-up study. Scand J Gastroenterol 2008;43(10):1269-74.

[54] Laine L, Cook D. Endoscopic ligation compared with sclerotherapy for treatment of esophageal variceal bleeding. A metaanalysis. Ann Intern Med 1995;123(4):280-7.

[55] Schmitz RJ, Sharma P, Badr AS, Qamar MT, Weston AP. Incidence and management of esophageal stricture formation, ulcer bleeding, perforation, and massive hematoma formation from sclerotherapy versus band ligation. Am J Gastroenterol 2001;96(2):437-41.

[56] Fry LC, Neumann H, Olano C, Malfertheiner P, Mönkemüller K. Efficacy, complications and clinical outcomes of endoscopic sclerotherapy with N-butyl-2-cyanoacrylate for bleeding gastric varices. Dig Dis 2008;26(4):300-3.

[57] Prachayakul V, Aswakul P, Chantarojanasiri T, Leelakusolvong S. Factors influencing clinical outcomes of Histoacryl ${ }^{\circledR}$ glue injection-treated gastric variceal hemorrhage. World J Gastroenterol 2013;19(15):2379-87.

[58] McClave SA, Chang WK. Complications of enteral access. Gastrointest Endosc 2003;58(5):739-51.

[59] Jafri NS, Mahid SS, Minor KS, Idstein SR, Hornung CA, Galandiuk S. Meta-analysis: antibiotic prophylaxis to prevent peristomal infection following percutaneous endoscopic gastrostomy. Aliment Pharmacol Ther 2007;25(6):647-56.

[60] Zopf Y, Rabe C, Bruckmoser T, Maiss J, Hahn EG, Schwab D. Percutaneous endoscopic jejunostomy and jejunal extension tube through percutaneous endoscopic gastrostomy: a retrospective analysis of success, complications and outcome. Digestion 2009;79(2):92-7.

[61] Manner H, May A, Miehlke S, Dertinger S, Wigginghaus B, Schimming W, et al. Ablation of nonneoplastic Barrett's mucosa using argon plasma coagulation with concomitant esomeprazole therapy (APBANEX): a prospective multicenter evaluation. Am J Gastroenterol 2006;101(8):1762-9. http://www.ncbi.nlm.nih.gov/pubmed?term=Niemann\%20G\%5BAuthor\% 5D\%26cauthor=true\%26cauthor_uid=16817835.

[62] Manner H, Plum N, Pech O, Ell C, Enderle MD. Colon explosion during argon plasma coagulation. Gastrointest Endosc 2008;67(7):1123-7.

[63] Shaheen NJ, Sharma P, Overholt BF, Wolfsen HC, Sampliner RE, Wang KK, et al. Radiofrequency ablation in Barrett's esophagus with dysplasia. N Engl J Med 2009;360(22):2277-88.

[64] Lyday WD, Corbett FS, Kuperman DA, Kalvaria I, Mavrelis PG, Shughoury AB, et al. Radiofrequency ablation of Barrett's esophagus: outcomes of 429 patients from a multicenter community practice registry. Endoscopy 2010;42(4):272-8.

[65] Inoue $\mathrm{H}$, Ikeda $\mathrm{H}$, Hosoya $\mathrm{T}$, Onimaru $\mathrm{M}$, Yoshida A, Eleftheriadis $\mathrm{N}$, et al. Submucosal endoscopic tumor resection for subepithelial tumors in the esophagus and cardia. Endoscopy 2012;44(3):225-30. http://www.ncbi.nlm.nih.gov/ pubmed?term=Kudo\%20S\%5BAuthor\%5D\%26cauthor=true\%26cauthor_uid=22354822.

[66] Ren Z, Zhong Y, Zhou P, Xu M, Cai M, Li L, et al. Perioperative management and treatment for complications during and after peroral endoscopic myotomy (POEM) for esophageal achalasia (EA) (data from 119 cases). Surg Endosc 2012;26(11): 3267-72.

[67] Xin L, Liao Z, Jiang YP, Li ZS. Indications, detectability, positive findings, total enteroscopy, and complications of diagnostic double-balloon endoscopy: a systematic review of data over the first decade of use. Gastrointest Endosc 2011;74(3):56370.

[68] Mensink PB, Haringsma J, Kucharzik T, Cellier C, Pérez-Cuadrado E, Mönkemüller K, et al. Complications of double balloon enteroscopy: a multicenter survey. Endoscopy 2007;39(7):613-5.

[69] Andriulli A, Loperfido S, Napolitano G, Niro G, Valvano MR, Spirito F, et al. Incidence rates of post-ERCP complications: a systematic survey of prospective studies. Am J Gastroenterol 2007;102(8):1781-8. http://www.ncbi.nlm.nih.gov/ pubmed?term=Forlano\%20R\%5BAuthor\%5D\%26cauthor=true\%26cauthor_uid=17509029.

[70] Williams EJ, Taylor S, Fairclough P, Hamlyn A, Logan RF, Martin D, et al. Risk factors for complication following ERCP; results of a large-scale, prospective multicenter study. Endoscopy 2007;39(9):793-801. 
[71] Wang P, Li ZS, Liu F, Ren X, Lu NH, Fan ZN, et al. Risk factors for ERCP-related complications: a prospective multicenter study. Am J Gastroenterol 2009;104(1):31-40.

[72] Freeman ML. Complications of endoscopic retrograde cholangiopancreatography: avoidance and management. Gastrointest Endosc Clin N Am 2012;22(3):567-86.

[73] Stapfer M, Selby RR, Stain SC, Katkhouda N, Parekh D, Jabbour N, et al. Management of duodenal perforation after endoscopic retrograde cholangiopancreatography and sphincterotomy. Ann Surg 2000;232(2):191-8.

[74] Kahaleh M, Freeman M. Prevention and management of post-endoscopic retrograde cholangiopancreatography complications. Clin Endosc 2012;45(3):305-12.

[75] Finsterer J, Stöllberger C, Bastovansky A. Cardiac and cerebral air embolism from endoscopic retrograde cholangiopancreatography. Eur J Gastroenterol Hepatol 2010;22(10):1157-62.

[76] Bisceglia M, Simeone A, Forlano R, Andriulli A, Pilotto A. Fatal systemic venous air embolism during endoscopic retrograde cholangiopancreatography. Adv Anat Pathol 2009;16(4):255-62.

[77] Efthymiou M, Raftopoulos S, Antonio Chirinos J, May GR. Air embolism complicated by left hemiparesis after direct cholangioscopy with an intraductal balloon anchoring system. Gastrointest Endosc 2012;75(1):221-3.

[78] Jenssen C, Alvarez-Sánchez MV, Napoléon B, et al. Diagnostic endoscopic ultrasonography: assessment of safety and prevention of complications. World J Gastroenterol 2012;18(34):4659-76.

[79] Adler DG, Jacobson BC, Davila RE, Hirota WK, Leighton JA, Qureshi WA, et al. ASGE guideline: complications of EUS. Gastrointest Endosc 2005;61(1):8-12.

[80] Affi A, Vazquez-Sequeiros E, Norton ID, Clain JE, Wiersema MJ. Acute extraluminal hemorrhage associated with EUSguided fine needle aspiration: frequency and clinical significance. Gastrointest Endosc 2001;53(2):221-5.

[81] Polkowski M, Larghi A, Weynand B, Boustière C, Giovannini M, Pujol B, et al. Learning, techniques, and complications of endoscopic ultrasound (EUS)-guided sampling in gastroenterology: European Society of Gastrointestinal Endoscopy (ESGE) Technical Guideline. Endoscopy 2012;44(2):190-206.

[82] Giovannini M. Endoscopic ultrasonography-guided pancreatic drainage. Gastrointest Endosc Clin N Am 2012;22(2): 221-30.

[83] Bakker OJ, van Santvoort HC, van Brunschot S, Geskus RB, Besselink MG, Bollen TL, et al. Endoscopic transgastric vs surgical necrosectomy for infected necrotizing pancreatitis: a randomized trial. J Am Med Assoc 2012;307(10):1053-61.

[84] Doi S, Yasuda I, Kawakami H, Hayashi T, Hisai H, Irisawa A, et al. Endoscopic ultrasound-guided celiac ganglia neurolysis vs. celiac plexus neurolysis: a randomized multicenter trial. Endoscopy 2013;45(5):362-9.

[85] Gupta K, Perez-Miranda M, Kahaleh M, Artifon EL, Itoi T, Freeman ML, et al., InEBD Study Group. Endoscopic ultrasoundassisted bile duct access and drainage: multicenter, long-term analysis of approach, outcomes, and complications of a technique in evolution. J Clin Gastroenterol 2013 Apr 29 [Epub ahead of print].

[86] Bokun T, Grgurevic I, Kujundzic M, Banic M. EUS-guided vascular procedures: a literature review. Gastroenterol Res Pract 2013;2013:865945.

[87] Manta R, Galloro G, Mangiavillano B, Conigliaro R, Pasquale L, Arezzo A, et al. Over-the-scope clip (OTSC) represents an effective endoscopic treatment for acute GI bleeding after failure of conventional techniques. Surg Endosc 2013 Feb 23 [Epub ahead of print].

[88] Sung JJ, Luo D, Wu JC, Ching JY, Chan FK, Lau JY, et al. Early clinical experience of the safety and effectiveness of Hemospray in achieving hemostasis in patients with acute peptic ulcer bleeding. Endoscopy 2011;43(4):291-5. http:// www.ncbi.nlm.nih.gov/pubmed?term=Ducharme\%20R\%5BAuthor\%5D\%26cauthor=true\%26cauthor_uid=21455870.

[89] Itoi T, Yasuda I, Doi S, Mukai T, Kurihara T, Sofuni A. Endoscopic hemostasis using covered metallic stent placement for uncontrolled post-endoscopic sphincterotomy bleeding. Endoscopy 2011;43(4):369-72.

[90] Baron TH, Wong Kee Song LM, Zielinski MD, Emura F, Fotoohi M, Kozarek RA. A comprehensive approach to the management of acute endoscopic perforations (with videos). Gastrointest Endosc 2012;76(4):838-59.

[91] Tam WY, Bertholini D. Tension pneumoperitoneum, pneumomediastinum, subcutaneous emphysema and cardiorespiratory collapse following gastroscopy. Anaesth Intensive Care 2007;35(2):307-9.

[92] Kowalczyk L, Forsmark CE, Ben-David K, Wagh MS, Chauhan S, Collins D, et al. Algorithm for the management of endoscopic perforations: a quality improvement project. Am J Gastroenterol 2011;106(6):1022-7.

[93] Minami S, Gotoda T, Ono H, Oda I, Hamanaka H. Complete endoscopic closure of gastric perforation induced by endoscopic resection of early gastric cancer using endoclips can prevent surgery (with video). Gastrointest Endosc 2006; 63(4):596-601.

[94] Mangiavillano B, Viaggi P, Masci E. Endoscopic closure of acute iatrogenic perforations during diagnostic and therapeutic endoscopy in the gastrointestinal tract using metallic clips: a literature review. J Dig Dis 2010;11(1):12-8.

[95] Otake Y, Saito Y, Sakamoto T, Aoki T, Nakajima T, Toyoshima N, et al. New closure technique for large mucosal defects after endoscopic submucosal dissection of colorectal tumors (with video). Gastrointest Endosc 2012;75(3):663-7.

[96] Matsuda T, Fujii T, Emura F, Kozu T, Saito Y, Ikematsu H, et al. Complete closure of a large defect after EMR of a lateral spreading colorectal tumor when using a two-channel colonoscope. Gastrointest Endosc 2004;60(5):836-8.

[97] Shi Q, Chen T, Zhong YS, Zhou PH, Ren Z, Xu MD, et al. Complete closure of large gastric defects after endoscopic fullthickness resection, using endoloop and metallic clip interrupted suture. Endoscopy 2013;45(5):329-34.

[98] Han JH, Lee TH, Jung Y, Lee SH, Kim H, Han HS, et al. Rescue endoscopic band ligation of iatrogenic gastric perforations following failed endoclip closure. World J Gastroenterol 2013;19(6):955-9.

[99] Rolanda C, Lima E, Silva D, Moreira I, Pêgo JM, Macedo G, et al. In vivo assessment of gastrotomy closure with over-thescope clips in an experimental model for varicocelectomy (with video). Gastrointest Endosc 2009;70(6):1137-45.

[100] Moreira-Pinto J, Lima E, Correia-Pinto J, Rolanda C. Natural orifice transluminal endoscopy surgery: a review. World J Gastroenterol 2011;17(33):3795-801.

[101] Vanuytsel T, Lerut T, Coosemans W, Vanbeckevoort D, Blondeau K, Boeckxstaens G, et al. Conservative management of esophageal perforations during pneumatic dilation for idiopathic esophageal achalasia. Clin Gastroenterol Hepatol 2012; 10(2):142-9.

[102] Lindenmann J, Matzi V, Neuboeck N, Anegg U, Maier A, Smolle J, et al. Management of esophageal perforation in 120 consecutive patients: clinical impact of a structured treatment algorithm. J Gastrointest Surg 2013;17(6):1036-43. 
[103] Van Boeckel PG, Dua KS, Weusten BL, Schmits RJ, Surapaneni N, Timmer R, et al. Fully covered self-expandable metal stents (SEMS), partially covered SEMS and self-expandable plastic stents for the treatment of benign esophageal ruptures and anastomotic leaks. BMC Gastroenterol 2012;12:19.

[104] Qadeer MA, Dumot JA, Vargo JJ, Lopez AR, Rice TW. Endoscopic clips for closing esophageal perforations: case report and pooled analysis. Gastrointest Endosc 2007;66(3):605-11.

[105] Kuehn F, Schiffmann L, Rau BM, Klar E. Surgical endoscopic vacuum therapy for anastomotic leakage and perforation of the upper gastrointestinal tract. J Gastrointest Surg 2012;16(11):2145-50.

[106] Hagel AF, Naegel A, Lindner AS, Kessler H, Matzel K, Dauth W, et al. Over-the-scope clip application yields a high rate of closure in gastrointestinal perforations and may reduce emergency surgery. J Gastrointest Surg 2012;16(11):2132-8.

[107] Balmadrid B, Kozarek R. Prevention and management of adverse events of endoscopic retrograde cholangiopancreatography. Gastrointest Endosc Clin N Am 2013;23(2):385-403.

[108] Lee TH, Bang BW, Jeong JI, Kim HG, Jeong S, Park SM, et al. Primary endoscopic approximation suture under cap-assisted endoscopy of an ERCP-induced duodenal perforation. World J Gastroenterol 2010;16(18):2305-10. http://www.ncbi.nlm. nih.gov/pubmed?term=Park\%20SH\%5BAuthor\%5D\%26cauthor=true\%26cauthor_uid=20458771.

[109] Voermans RP, Le Moine O, von Renteln D, Ponchon T, Giovannini M, Bruno M, et al., CLIPPER Study Group. Efficacy of endoscopic closure of acute perforations of the gastrointestinal tract. Clin Gastroenterol Hepatol 2012;10(6):603-8. http://www.ncbi.nlm.nih.gov/pubmed?term=Seewald\%20S\%5BAuthor\%5D\%26cauthor=true\%26cauthor_uid=22361277.

[110] Canena J, Liberato M, Horta D, Romão C, Coutinho A. Short-term stenting using fully covered self-expandable metal stents for treatment of refractory biliary leaks, postsphincterotomy bleeding, and perforations. Surg Endosc 2013;27(1):313-24.

[111] Magdeburg R, Collet P, Post S, Kaehler G. Endoclipping of iatrogenic colonic perforation to avoid surgery. Surg Endosc 2008;22(6):1500-4.

[112] Kang HY, Kang HW, Kim SG, Kim JS, Park KJ, Jung HC, et al. Incidence and management of colonoscopic perforations in Korea. Digestion 2008;78(4):218-23.

[113] Yang DH, Byeon JS, Lee KH, Yoon SM, Kim KJ, Ye BD, et al. Is endoscopic closure with clips effective for both diagnostic and therapeutic colonoscopy-associated bowel perforation? Surg Endosc 2010;24(5):1177-85.

[114] Murariu D, Tatsuno BK, Tom MK, You JS, Maldini G. Subcutaneous emphysema, pneumopericardium, pneumomediastinum and pneumoretroperitoneum secondary to sigmoid perforation: a case report. Hawaii J Med Public Health 2012;71(3):74-7. 